\title{
Buckleyella ornata n. sp. (Nematoda: Philometridae) from the abdominal cavity of the talang queenfish Scomberoides commersonnianus (Perciformes: Carangidae) off the northern coast of Australia
}

\author{
F. MORAVEC ${ }^{1}$, B. DIGGLES ${ }^{2}$, L. BARNES ${ }^{3}$, W. MACBETH ${ }^{3}$ \\ ${ }^{1}$ Institute of Parasitology, Biology Centre of the Academy of Sciences of the Czech Republic, Branišovská 31, \\ 37005 České Budějovice, Czech Republic, *E-mail: moravec@paru.cas.cz; ${ }^{2}$ DigsFish Services Pty Ltd., \\ Banksia Beach, Australia; ${ }^{3}$ Cardno, PO Box 19, St Leonards NSW 1590, Australia
}

\begin{abstract}
Summary
A new nematode species, Buckleyella ornata n. sp. (Philometridae), is described from female specimens found in the abdominal cavity (mesenteries) of the talang queenfish Scomberoides commersonnianus Lacepède (Carangidae, Perciformes) caught in Darwin Harbour, northern Australia. Based on light and scanning electron microscopical examination, the new species mainly differs from the only other congeneric species B. buckleyi Rasheed, 1963 in having a markedly shorter oesophagus $(2.04-2.75 \mathrm{~mm}$ long), by the absence of a cephalic mound around the mouth aperture, by the presence of four submedian cephalic papillae of the inner circle, and by a somewhat different arrangement of cuticular ornamentations on the body surface. Three protruding oesophageal teeth and large, dome-shaped cephalic papillae of the external circle present in the smallest gravid female of $B$. ornata are atrophied in larger conspecific gravid females. Buckleyella ornata is the first known nominal species of a philometrid parasitizing carangid fishes in Australian waters.
\end{abstract}

Keywords: Parasitic nematode; new species; Dracunculoidea; marine fish; Darwin Harbour

\section{Introduction}

The present knowledge of philometrid nematodes (Philometridae) parasitizing marine fishes in Australian waters is relatively poor (Johnston \& Mawson, 1940; Rasheed, 1963; Moravec \& Rohde, 1992; Hesp et al., 2002; Moravec \& Diggles, 2014). During parasitological investigations on some marine fishes in Darwin Harbour, northern Australia carried out in 2013, philometrid nematodes (only females) were found in the mesenteries of the talang queenfish Scomberoides commersonnianus Lacepède (Carangidae, Perciformes). Close examination revealed that they represented a new species of the hitherto monotypic genus Buckleyella Rasheed, 1963, which is described be- low. Scomberoides commersonnianus (maximum body length $120 \mathrm{~cm}$, maximum weight $16 \mathrm{~kg}$ ) is a tropical marine commercial and game fish which occurs throughout the tropical and subtropical Indo-West Pacific region. Adult queenfish inhabit coastal waters, frequently near reefs and offshore islands (Froese \& Pauly, 2014).

\section{Materials and methods}

Queenfish ( $\mathrm{n}=36$, mean fork length (FL) $47.6 \mathrm{~cm}$, range $30.4-76.1 \mathrm{~cm}$, mean weight $1.2 \mathrm{~kg}$, range $0.308-4.8 \mathrm{~kg}$ ) were collected using a gill net from Darwin Harbour $\left(12^{\circ} 29^{\prime} \mathrm{S}, 130^{\circ} 49^{\prime} \mathrm{E}\right)$ in October 2013 and both Darwin Harbour and Bynoe Harbour $\left(12^{\circ} 41^{\prime} \mathrm{S}, 130^{\circ} 34^{\prime} \mathrm{E}\right.$ ), in March 2014. They were euthanased by brain destruction (iki-jime), placed in a sealed plastic bag and stored on ice for transportation back to the laboratory for further examination. At the laboratory the fish was measured (length/weight) and examined externally by eye for lesions. The paired fins (pectoral/pelvic), operculum and gill arches on the left side of each fish were then excised and examined under a dissection microscope. The fish was then cut open and all internal organs were grossly examined for parasites and then were fixed in $4 \%$ formalin.

The philometrid nematodes obtained were washed in physiological saline and were then fixed and preserved either in $4 \%$ formalin or $70 \%$ ethanol. Formalin-fixed viscera of the infected fish specimen were also thoroughly examined for a possible presence of conspecific philometrid males, but no males were found. For light microscopical examination, the nematodes were cleared with glycerine. Drawings were made with the aid of a Zeiss drawing attachment. Specimens used for scanning electron microscopy (SEM) were postfixed in $1 \%$ osmium tetroxide (in phosphate buffer), dehydrated through a graded acetone series, critical-point-dried and sputter-coated with gold; they were examined using a JEOL JSM-7401F scan- 
ning electron microscope at an accelerating voltage of $4 \mathrm{kV}$ (GB low mode). All measurements are in micrometres unless otherwise indicated. The fish nomenclature adopted follows FishBase (Froese \& Pauly, 2014).

\section{Results}

Family Philometridae Baylis et Daubney, 1926

\section{Buckleyella ornata $\mathrm{n}$. sp.}

(Figs. 1-3)

Description: Female (2 complete and 3 fragmented specimens; measurements of holotype in parentheses): Body of live specimens red-coloured; fixed specimens yellowish with dark-brown intestine visible through cuticle, filiform, 40 - 180 (180) mm long; maximum width $390-1,170$
$(1,170)$ at region just posterior to oesophagus; body tapering at both ends. Width of cephalic end $286-367$ (367), of posterior end 122 - 381 (381). Maximum width/length ratio of body 1:102 - 154 (1:154). Except for ends, body rectangular to nearly square-shaped at cross-section, with broad lateral fields formed by smooth, transversely wrinkled cuticle (Fig. 3F); cuticle of dorsal and ventral sides of body with numerous rod-like cuticular mounds situated on top of transversely elongated elevations of cuticle up to 272 (272) wide, appearing at body margin as small elevated bosses (Figs. 1F,I - K, 2C-G, 3C,E,F); these ornamentations arranged in patterns covering body surface from anterior to posterior ends in larger specimens, but starting at rather long distance posterior to cephalic extremity in smallest specimen (Fig. 2D). Cephalic end truncated. Oral aperture oval, surrounded by 8 medium-sized cephalic papillae of external circle arranged in 4 subme-

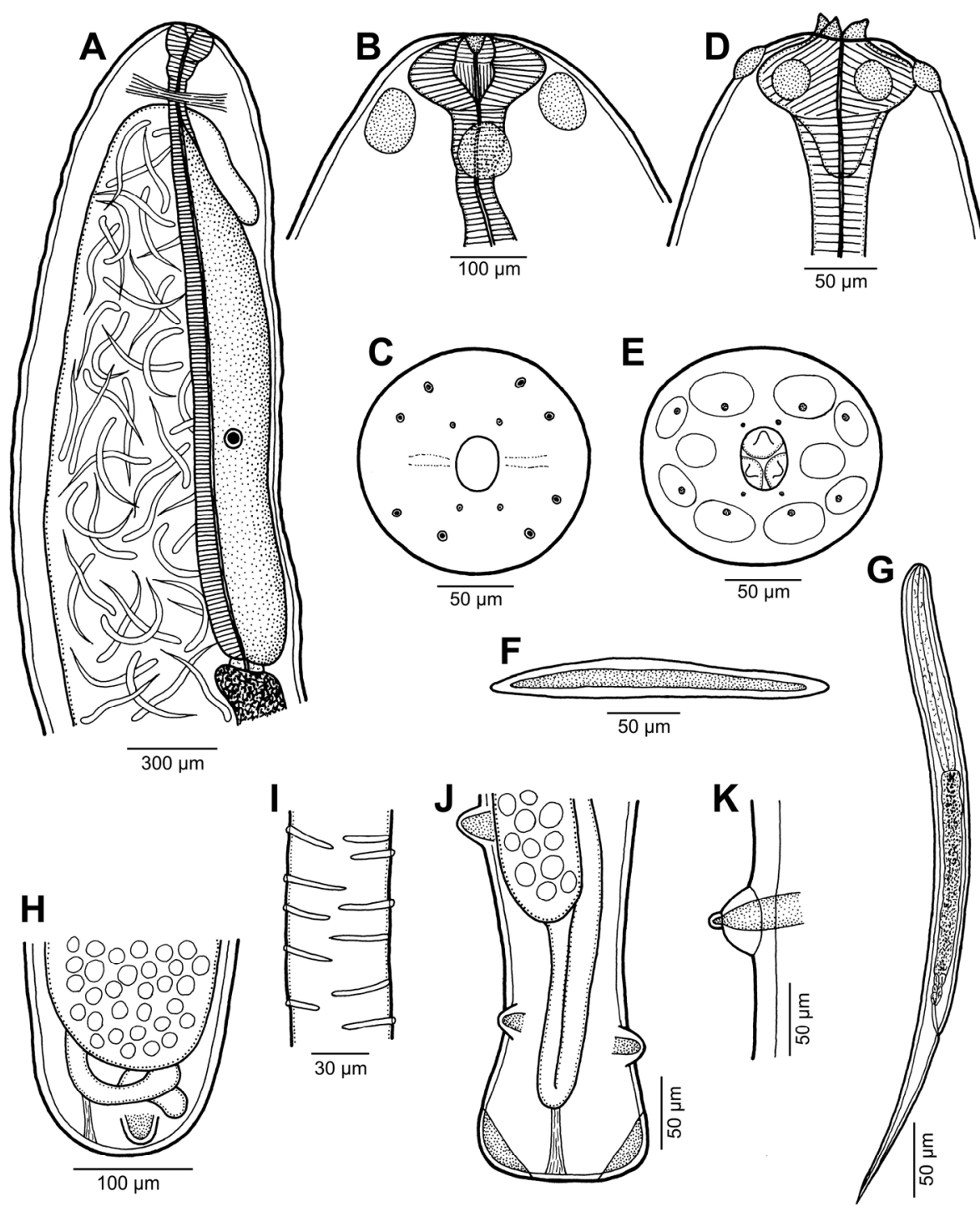

Fig. 1. Buckleyella ornata sp. n., gravid females. A - anterior end of larger specimen, lateral view; B,D - cephalic end of larger and smallest specimens, respectively, lateral views; C,E - cephalic and of larger and smallest specimens, respectively, apical views; F - rod-like mound on transversely elongated cuticular elevation; $\mathrm{G}$ - larva from uterus; $\mathrm{H}$ - caudal end of larger specimen, lateral view; I - dorsal cuticular ornamentations at mid-body of larger specimen; $\mathrm{J}$ - caudal end of smallest specimen, dorsoventral view; $\mathrm{K}$ - cuticular ornamentation, lateral view 


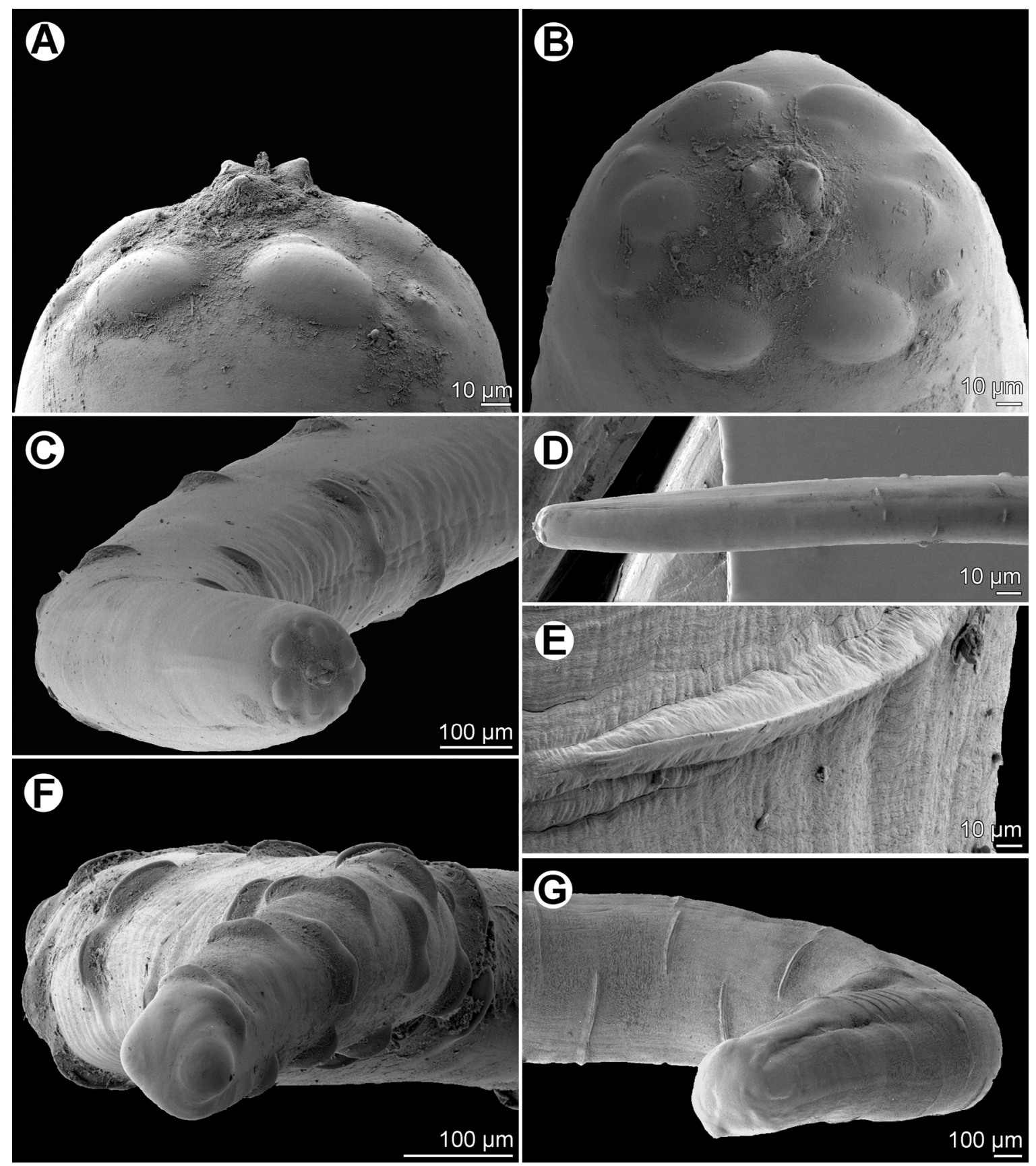

Fig. 2. Buckleyella ornata sp. n., scanning electron micrographs of gravid females. A,B - cephalic end of smallest specimen, dorsal and apical views, C,D - anterior end of smallest specimen, different positions, E - cuticular ornamentation, subapical view, $\mathrm{F}, \mathrm{G}-$ caudal end of smallest and larger specimens, respectively

dian pairs, and 4 smaller submedian papillae of internal circle; each external papilla situated on top of large, domeshaped elevation filled with glandular tissue in smallest specimen (40 mm long) (Figs.1D,E, 2A,B); such elevations not discernible in larger specimens, but respective oval glandular formations still observable inside tissue surrounding anterior oesophageal bulb (Figs. 1B,C, 3A - D). Two large lateral dome-shaped elevations present in smallest specimen (Figs. 1E, 2A,B), probably representing amphids without outlets, are absent in larger specimens (Figs. 1C, 3A - D). Three conspicuous, conical oesophageal teeth 21 high protruding out of mouth in smallest specimen 232
(Figs. 1D,E, 2A,B), but absent in larger specimens (Figs. $1 \mathrm{~A}, \mathrm{~B}, 3 \mathrm{~A}-\mathrm{D})$. Anterior end of oesophagus forms distinct onion-shaped bulb $204-258$ (245) long and $204-258$ (245) wide. Oesophagus muscular, provided with large oesophageal gland extending from its posterior end to level of nerve ring; oesophageal gland with large cell nucleus at middle (Fig. 1A). Entire oesophagus including anterior bulb $2.04-2.75(2.75) \mathrm{mm}$ long, representing $2-6(2) \%$ of body length; maximum width of oesophagus including oesophageal gland $204-367$ (367). Small ventriculus $54-$ 68 (68) long and $109-150$ (150) wide present. Nerve ring and cell nucleus of oesophageal gland $272-381$ (340) and 

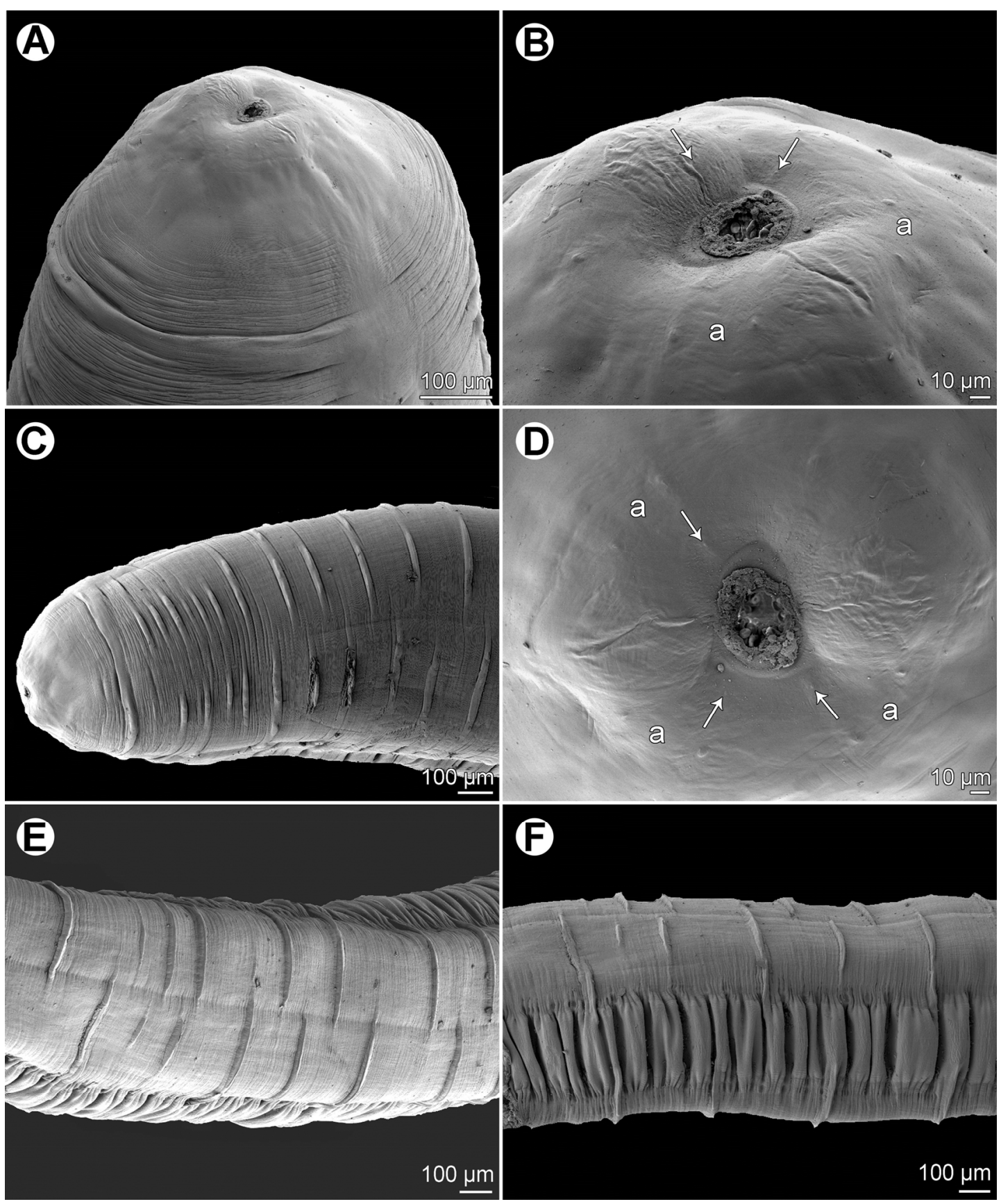

Fig. 3. Buckleyella ornata sp. n., scanning electron micrographs of larger gravid female. A,B cephalic end at different magnifications, sublateral view (arrows indicate internal cephalic papillae), $\mathrm{C}$ - Anterior end of body, dorsoventral view, D - cephalic end, apical view (arrows indicate internal cephalic papillae), E,F - middle part of body, dorsoventral and lateral views. Abbreviation: a - pair of external cephalic papillae

1.16 - 1.89 (1.89) mm, respectively, from anterior extremity (Fig. 1A). Intestine dark-brown, narrow, its posterior part attached by ligament to ventral body wall near posterior extremity. Ovaries reflexed, situated near body ends (Fig. 1A,H,J). Uterus occupying almost entire space of body, reaching anteriorly to level of nerve ring and posteriorly almost to body end in larger specimens. Vagina and vulva absent. Uterus contains numerous larvae at its anterior portion and many eggs at posterior part. Larvae $(\mathrm{n}=5)$ $450-480$ long and $15-18$ wide, with rounded anterior and sharply pointed posterior ends (Fig. 1G); length of oesophagus $135-156$ (28 - 35\% of body length), of tail $108-126$ ( $23-27 \%$ of body length). Posterior end of body of adults narrow, rounded, with rather large rounded lateral caudal projections (Figs. 1H,J, 2F,G).

Male: Unknown.

Taxonomic summary

Type host: Talang queenfish Scomberoides commersonnianus Lacepède (Carangidae, Perciformes); female, $76.1 \mathrm{~cm}$ (FL), weight $4.8 \mathrm{~kg}$. 
Site of infection: Abdominal cavity (mesenteries).

Type locality: Darwin Harbour, northern Australia (collected 9 October 2013).

Prevalence and intensity: 1 fish infected/36 fish examined; 5 nematode specimens. These worms were found only in the largest female queenfish sampled, which had well developed, late stage gonads (gonad weight $185 \mathrm{~g}$ ). They were not observed in other $S$. commersonnianus $(\mathrm{n}=59$, mean FL $49.7 \mathrm{~cm}$, range $26.0-76.0 \mathrm{~cm}$ ) examined for internal nematodes from northern Australia during previous sampling events between August 2012 and March 2013 as described by Moravec and Diggles (2014), suggesting the overall population prevalence for this parasite may be around $1.05 \%$ (1 fish infected/95 fish examined).

Type specimens: Holotype and paratypes (SEM stubs and body fragments in vials) in the Helminthological Collection of the Institute of Parasitology, Biology Centre of the Academy of Sciences of the Czech Republic, České Budějovice (Cat. No. N-1049).

Etymology: The specific name of this nematode is a Latin adjective (ornata $=$ ornamental) relating to characteristic cuticular ornamentations on the body surface.

\section{Discussion}

In having typical cuticular ornamentations on the body surface (presence of transversely elongated elevations bearing rod-like formations) and a similar general morphology, these specimens belong to the hitherto monotypic genus Buckleyella. This is also supported by the fact that they were collected from a fish congeneric to the host of the only other species of this genus, B. buckleyi Rasheed, 1963, and the site of infection (mesenteries) of these two forms is identical. However, the presence of conspicuous oesophageal teeth and large dome-shaped cephalic papillae, diagnosed for Buckleyella by Rasheed (1963), were observed only in the smallest specimen, whereas these features were absent from available larger specimens. Probably the conical oesophageal teeth (three anterior oesophageal lobes protruding out of the mouth) and the dome-shaped elevations of cephalic papillae gradually disapper as the gravid female nematodes increase in size. The presence/absence of oesophageal teeth in conspecific philometrid gravid and subgravid females were also observed in Philometra sp. from the subcutaneous tissue of Mycteroperca microlepis (Goode et Bean) (Serranidae) in the Gulf of Mexico and in Spirophilometra endangae Dewi et Palm, 2013, a parasite of fins of Epinephelus coioides (Hamilton) (Serranidae) off Indonesia and Australia (Moravec et al., 2010; Moravec \& Diggles, 2014).

The only species of Buckleyella, B. bukleyi, was described by Rasheed (1963) based on available female specimens collected from the mesentery of the carangid Scomberoides tala (Cuvier) (reported as Chorinemus tala) from off the coast of Pakistan. Later, B. buckleyi was reported by Parukhin (1966, 1971) from the type host and from Scomberoides lysan (Forsskål) from the Red and South
China Seas (see also Moravec, 2006). Type specimens of B. buckleyi, housed in the Natural History Museum, London, were re-examined by Moravec and Harris (2010), who had also examined by SEM one non-type specimen of Rasheed's original collection.

The general morphology and measurements of gravid females of B. ornata n. sp. are similar to those of B. buckleyi, but the former species distinctly differs from the latter in having a conspicuously shorter oesophagus $(2.04-2.75$ $\mathrm{mm}$ vs. $3.96-5.10 \mathrm{~mm}$ ), although the specimens were mostly larger than B. buckleyi specimens described by Rasheed (1963). In addition, the oral aperture of B. buckleyi is surrounded by a marked cephalic mound separated from the rest of the body by a deep groove (Moravec \& Harris, 2010), which is absent in the new species. Buckleyella ornata also differs in possessing four submedian cephalic papillae of the inner circle (not observed in $B$. bucklyei). Moreover, the anterior oesophageal bulb of $B$. buckleyi is distinctly broader $(204-258 \mu \mathrm{m}$ vs. $140-$ $150 \mu \mathrm{m})$ and the distribution of cuticular ornamentations on the anterior end of body seems to be different (see Fig. 2C of Moravec \& Harris, 2010 and Fig. 3C of the present paper); the presence of prominent broad lateral fields without characteristic ornamentations, extending along the body, were not reported for B. buckleyi. It can be expected that more interspecific features will be found when the so far unknown males of these two species are discovered and described.

The three large conical oesophageal teeth as in B. buckleyi and in the smallest specimen of B. ornata of the present material were also described in a few representatives of two other philometrid genera, Caranginema americanum Moravec, Montoya-Mendoza et Salgado-Maldonado, 2008, a subcutaneous parasite of Carax hippos (Linnaeus) (Carangidae) in the Gulf of Mexico (Moravec et al., 2008), Philometra sydneyi Rasheed, 1963, a poorly known parasite of the subcutaneous tissue of an unidentified "large white fish" (a carangid?) from Sydney, Australia (Rasheed, 1963), and Philometra tricornuta Moravec et Ali, 2014 from the musculature of Saurida tumbil (Bloch) (Synodontidae) in the Persian Gulf (Moravec \& Ali, 2014). Large conical oesophageal teeth, similar to those of Buckleyella spp., were also illustrated by Deardorff et al. (1986) for an unidentified Philometra sp. observed under the skin and in the musculature of Caranx melampygus Cuvier (Carangidae) off Hawaii.

As mentioned by Rasheed (1963), the cuticularized oesophageal teeth of B. buckleyi can be moved in and out of the mouth and are used primarily in the penetration of the blood vessels and the tissues. Although the author writes that "the cuticularized teeth are most certainly present in all the stages of development", in fact she found two gravid specimens (out of about 30 examined) to be devoid of these teeth and possessing "smaller head papillae". However, it can be deduced from the available specimens of $B$. ornata that protruding oesophageal teeth and largesized external cephalic papillae occur in small-sized gravid females of this species; but gravid females continue to 
grow considerably and their oesophageal teeth and largesized external cephalic papillae are gradually atrophied during this process. The present data indicate that the gravid females of $B$. ornata may increase their body length 4.5 times (twice in B. buckleyi).

Fishes of the Carangidae are frequently found to be infected with philometrid species of Buckleyella, $\mathrm{Ca}$ ranginema Moravec, Montoya-Mendoza et Salgado-Maldonado, 2008, Philometra Costa, 1845 and Philometroides Yamaguti, 1935, which parasitize different organs of their hosts (Moravec, 2006; Moravec et al., 2008; Moravec \& Justine, 2014). Buckeyella ornata $\mathrm{n}$. sp. is the first nominal species of the Philometridae known to parasitize carangid fishes in Australian waters.

\section{Acknowledgements}

For their help with field collections, we thank field staff from Cardno and Quentin Allsop, Wayne Baldwin, and Chris Errity from NT Fisheries. The field sampling for this project was undertaken by DigsFish Services under contract to Cardno as part of the Nearshore Environmental Monitoring Program. Authors' thanks are also due to the staff of the Laboratory of Electron Microscopy, Institute of Parasitology, Biology Centre of the AS CR, České Budějovice for their technical assistance, and to Blanka Škoríková of the same Institute for help with illustrations. This study was partly supported by the Czech Science Foundation (grant No. P505/12/G112) and the Institute of Parasitology, BC AS CR (institutional support RVO:60077344).

\section{References}

DeArdorfF, T. L., Overstreet, R. M., OKihiro, M., TAM, R. (1986): Piscine adult nematode invading an open lesion in a human hand. Am. J. Trop. Med. Hyg., 35: 827 830

Froese, R., PAuly, D. (Eds) (2014): FishBase. World Wide Web electronic publication. http://www.fishbase.org, version $02 / 2014$

Hesp, S. A., Hobbs, R. P., PotTer, I. C. (2002): Infection of the gonads of Glaucosoma hebraicum by the nematode Philometra lateolabracis: occurrence and host response. J. Fish Biol., 60: 663 - 673

Johnston, T. H., Mawson, P. (1940): Some nematodes parasitic in Australian freshwater fish. Trans. Roy. Soc. S. Austr., 64: 340 - 352
Moravec, F. (2006): Dracunculoid and anguillicoloid nematodes parasitic in vertebrates. Academia, Prague, 634 pp. Moravec, F., Ali, A. H. (2014): Additional observations on Philometra spp. (Nematoda: Philometridae) in marine fishes off Iraq, with the description of two new species. Syst. Parasitol., 87: 259 - 271. DOI: 10.1007/s11230-0149475-6

Moravec, F., Bakenhaster, M., Fajer-Ávila, E. J. (2010): New philometrids (Nematoda, Philometridae) from head tissues of two serranid fishes (Epinephelus morio and Mycteroperca microlepis) off Florida, northern Gulf of Mexico. Acta Parasitol., 55: 359 - 368. DOI: 10.2478/s11686-010-0057-8

Moravec, F., Diggles, B. (2014): Philometrid nematodes (Philometridae) from marine fishes off the northern coast of Australia, including three new species. Folia Parasitol., 61: $37-54$

MoraVec, F., HARris, E. (2010): Structure of the female cephalic end and cuticular ornamentations of Buckleyella buckleyi Rasheed, 1963 (Nematoda: Philometridae), as revealed by SEM. J. Parasitol., 96: 666 - 668. DOI: http://dx.doi.org/10.1645/GE-2354.1

Moravec, F., Justine, J.-L. (2014): Philometrids (Nematoda: Philometridae) in carangid and serranid fishes off New Caledonia, including three new species. Parasite, 21: 21. DOI: $10.1051 /$ parasite/2014022

Moravec, F., Montoya-Mendoza, J., SAlgadoMALDONADO, G. (2008): A new genus and species of philometrid (Nematoda) from the subcutaneous tissue of the crevalle jack, Caranx hippos (Osteichthyes), from the southern Gulf of Mexico. J. Parasitol., 94: 1346 - 1350. DOI: $10.1645 / \mathrm{GE}-1577.1$

Moravec, F., RoHDE, K. (1992): Three species of nematodes of the superfamily Dracunculoidea from Australian fishes. Acta Soc. Zool. Bohemoslov., 56: 187 - 195

PARUKHIN, A. M. (1966): Studies on the helminth fauna of fishes of the family Carangidae from the South China Sea. In: Delyamure S. L. (Ed), Gelmintofauna zhivotnykh yuzhnykh morey. Naukova Dumka, Kiev, pp. 80 - 96 (In Russian)

PARUKHIN, A. M. (1971): Nematodes from fishes of the Red Sea and Indian Ocean. In: Delyamure S. L. (Ed), Voprosy ekologii ryb yuzhnikh morey. Biologiya morya 23. Naukova Dumka, Kiev, pp. 177 - 193 (In Russian)

RASHEED, S. (1963): A revision of the genus Philometra Costa, 1845. J. Helminthol., 37: $89-130$ 